\title{
Art for science
}

\author{
Scientists and engineers should embrace art as a part of their work.
}

$\mathrm{T}$ raditional thinking imposes that the arts and sciences are rooted in opposite values: creativity, imagination and freedom of thought for the former; rationality, rigorousness and acceptance of laws for the latter. But are they?

Underneath the surface of disciplinary stereotypes there is something much more fundamental, something universal.

Both being human endeavours, art and science are entrenched with passion, desire, success, struggle, fear, envy and awe. They originate from an all-so-human need to understand the world in which we have been put without our asking for it. How much more common ground could they have than this shared fundamental quest? Every other label associated with art or science is an artificial tag to justify one enterprise over the other, but has little sense.

It is undeniable, though, that scientists and artists look at the world from different angles. But herein lies the richness of the cross-fertilization between the two fields. In this issue of Nature Nanotechnology we have collected experiences of artists whose work is inspired by scientific or technological advances. By reading these contributions, the range of benefits scientists can enjoy from engaging with artists should become clear.

A first benefit is linked to the engagement that art has with the general public. Artists are trained to generate an emotional response in their viewership, something that scientists are not well-equipped for. With their aura of objectivity, scientists may end up increasingly isolated. And it is not smart for scientists to distance themselves from their most generous source of funding - the taxpayer. Anti-scientific sentiments, such as scepticism towards the efficacy of vaccines, flat Earth activists or climate change denials, are there to remind us that science - the scientific method - cannot be taken for granted. A post-truth society demands that scientists speak out; it is no longer enough to produce data and explain error bars, hoping facts will be objectively interpreted by everyone in the same way. It is necessary to explain, first and foremost, the mechanisms of science; defending the reputation of the institution of science, as a means to defend facts. In a sense, the scientific method is like democracy in that it needs to be protected day by day. Art can be the perfect liaison

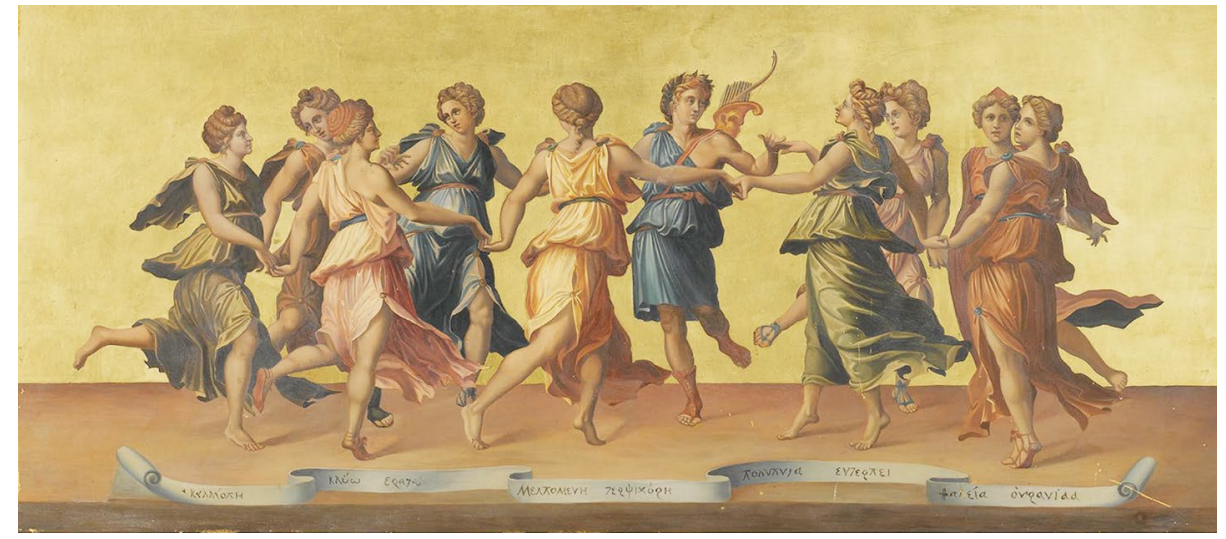

Credit: Heritage Image Partnership Ltd/Alamy Stock Photo

between the highly specialized work of the scientists and the lay person. Art could become the loudspeaker science needs to re-establish itself as a trustworthy source of knowledge.

A second benefit, perhaps more immediate for scientists, is linked to the continual exchange of views with artists. In particular, through their constant raising of provocative, sometimes unpleasant questions, artists force scientists to confront other creative thinkers outside their circle. This practice exercises scientists' ability to think outside the box and deepen their lateral thinking skills. Overall, they are both curious, creative and critical folks. Exploring their diversity is bound to lead to numerous sources of inspiration for both. And that can only be a good thing for science. Besides, scientists may come to appreciate their work in a more satisfactory way, because art can bring out the beauty in what they do.

A third, related, benefit is linked to the possible impact of future technologies on our daily lives. Art has the possibility to display in a tangible way future worlds to the public before these become reality, and, crucially, before all important political and ethical choices have been made. It is a primary responsibility of scientists and engineers to keep the public informed about the societal implications of their work. Being a third, independent group, artists are well-placed to foster this dialogue. An example, among many, is the use of artificial intelligence, machine learning and robotics, an enterprise that is now occupying a large number of engineers and is bound to profoundly change our society. Artists experimenting with prototype tools are already speculating about future worlds and bringing to the attention of the general public some of the prospective scenarios. In fact, artificial intelligence seems to be the new avant-garde in art at the moment, as Arthur I. Miller explains in his Comment.

The small collection we have put together (https://go.nature.com/2DvloI0) does not intend to be exhaustive, but we hope it can be a starting point for many scientists (in nanoscience and beyond) to research the art scene in their region and find valuable links to start collaborating with artists. It should be clear that, though fascinated by science and engineering, artists usually have very little technical knowledge. Therefore, scientists need to be prepared to invest resources and time in these kinds of collaborations. However, there are art galleries around the world already hosting exhibitions dedicated to science and technology. There are scholarly journals and art magazines dedicated to this crossdisciplinary artistic field. There are actors, choreographers and musicians taking the lead from science to produce engaging and entertaining shows. It's time more scientists get involved.

Published online: 7 May 2019

https://doi.org/10.1038/s41565-019-0459-1 